\title{
ÚLTIMA ETAPA DEL INFORMALISMO EN EL PAÍS CON SUPERVIVENCIA (1971) DE LOLA FERNÁNDEZ CABALLERO (1926-)
}

\author{
The last stage of informalism in Costa Rica with Superviviencia (1971) \\ from Lola Fernández Caballero (1926-)
}

\author{
Daniel Adolfo Montero Rodríguez \\ Universidad de Costa Rica, Costa Rica \\ danielmont84@gmail.com
}

Recibido: 20-02-2019

Aprobado: 29-03-2019

\section{Daniel Montero Rodríguez es Bachiller y Licenciado en Artes Plásticas con énfasis en Pintura, y Máster en Artes con énfasis en Artes Visuales, todas por la Universidad de Costa Rica. Actualmente labora como profesor de las carreras de Artes Plásticas de la Universidad de Costa Rica en la Sede de Occidente.}

\section{RESUMEN}

El presente artículo consiste en un estudio semiótico de la pintura costarricense de la década de los setenta de siglo $\mathrm{XX}$, sobre el proceso de finalización de la pintura no-figurativa, concretamente el informalismo de la artista Lola Fernández presente en su obra Supervivencia (1971). Metodológicamente, se acude al análisis semiótico del texto artístico, a través de un proceso gradual de interpretación del signo en tres niveles (sintáctico, semántico y pragmático). Además, como acercamiento teórico, se conceptualiza la noción de "informalismo" y "arte abstracto". También, se refiere al contexto socio-histórico costarricense de la I Bienal Centroamericana de Pintura (1971). De esta manera, se consigue percibir como el veredicto de dicho certamen tuvo una influencia patente en el proceso de finalización de la no-figuración costarricense, asimismo, se revelan referencialidades no antes observadas, u obviadas por la crítica, en Supervivencia (1971) de esta pintora costarricense.

Palabras clave: semiótica; informalismo; no-figuración; pintura costarricense; Lola Fernández Caballero

\begin{abstract}
The present article consists in a semiotic study of the Costa Rican painting during the decade of the seventies in the 20th century, as well as the end of the non-figuration painting, and with a special emphasis on the informalism present in "Supervivencia" (1971) from artist Lola Fernández. Methodologically speaking, we turn to the semiotic analysis of the artistic text, through a gradual process of interpretation of the sign in three levels (syntactic, semantic and pragmatic). Furthermore, both notions of "informalism" and "abstract art" are conceptualized in this article using a theoretical approach. In addition, this study will refer to the socio-historical context of the I Bienal Centroamericana de Pintura (First Central American Painting Biennial), which took place in 1971. As a result of the previously stated approaches, we will be able to determine how the verdict of the Bienal propelled the Costa Rican non-figuration painting movement to come to an end. Likewise, we disclose refentialities in "Supervivencia" (1971) that were either never seen before, or were maybe omitted by the art critics of that time.
\end{abstract}

Keywords: semiotics; informalism; non-figuration; Costa Rican painting; Lola Fernández Caballero 


\section{Introducción}

La labor pictórica de Lola Fernández Caballero es significativa para el acontecer costarricense, debido a que es quien presenta la primera obra no-figurativa en el país, hecha por una mujer. Se puede decir que, con la representación femenina de la no-figuración, se da inicio al estilo que generó ruptura en la plástica de Costa Rica, implantando una visión más vanguardista. La artista ha dedicado gran parte de su vida a especializarse en pintura, realizando estudios en esta área tanto en Costa Rica, Colombia, Italia, como en Oriente. Con esta base académica, ha conocido todos los ámbitos de la pintura hasta llegar, en los años sesenta, a su obra abstracta:

Inicios y abstracción. Lola Fernández (Cartagena, Colombia, 1926) ingresó en la Escuela de Bellas Artes de la Universidad de Costa Rica en la década de 1940; en 1946 viajó a Bogotá para especializarse en pintura en la Escuela de Bellas Artes de la Universidad Nacional de Colombia, y en 1954 profundizó su conocimiento pictórico en la Academia de Bellas Artes de Florencia, Italia (Triana, 2012, párr. 13).

Con estos conocimientos regresó de Italia y mostró al público costarricense no solo sus capacidades en el ámbito pictórico sino, a su vez, presentó a la plástica del país nuevos horizontes estéticos y conceptuales: "Dispuso exponer en el Museo Nacional, ya que ofrecía dos salas adecuadas para tal cosa. Y así el 29 de mayo de 1958 quedó inaugurada su exhibición, auspiciada por la Universidad de Costa Rica y con participación del entonces rector Carlos Monge Alfaro, convirtiéndose ésta en la primera exposición de arte abstracto realizada en Costa Rica" (Zavaleta, 1993, p. 256). En este sentido, se presentó la primera obra no-figurativa que conoce el espectador nacional, inaugurando un despertar para la plástica que, hasta entonces, solo se relacionaba con tendencias que aun conservaban el academicismo muy arraigado.

Otro rasgo significativo, al estudiar la pintura de esta artista, es el hecho de que representa el trabajo de la mujer y su capacidad para desenvolverse en cualquier ámbito, pues hasta entonces, la obra pictórica estaba relegada al reconocimiento del hombre, a pesar de que existían mujeres que se dedicaban a la pintura. Lola Fernández es la gran representante, tanto por su función rupturista como por su intensa labor dentro de la pintura costarricense: "Esto convierte a Lola Fernández en una de las pioneras que encausan el arte local hacia la búsqueda de la equidad de géneros, ya que a partir de su propuesta la tradicional posición relegada de la mujer ya no será la misma" (Rojas, 2003, p. 112). Esto es importante en la medida en que presenta un valor agregado a la obra de dicha artista. Sin embargo, no es un asunto medular para el análisis de los significados de su producción como obra abstracta. 
El gran conocimiento que maneja sobra la pintura, ser la primera representante de la no-figuración costarricense, así como una propulsora de la igualdad de género, esto sin hablar de su vasta labor pictórica, son razones para estudiar el trabajo pictórico de Lola Fernández como paradigma del informalismo ${ }^{1}$ en Costa Rica.

Por otra parte, la obra pictórica de Fernández es muy variada. Se ha desenvuelto tanto dentro de la figuración como dentro de la abstracción. En 1979, se establecieron tres etapas dentro de su plástica no-figurativa; no se contempló la figuración que realizaba durante estas etapas, ni se mencionó su posterior trabajo figurativo, una vez concluida la fase abstracta en el país:

La pintora -a grandes rasgos- considera tres períodos en su evolución abstracta. El dominado por singular preocupación espacial. Las estructuras, bastante asimétricas, se construyen por el contraste de zonas espaciales y grandes masas. Uso paciente de veladuras dirigidas a conformar un colorido por transparencias. El período de la máquina, de espacios simples y acumulación de elementos. En ellos diferentes obras rememoran cierto racionalismo de la mancha, aunque en otras defina mayor dinamismo desde un formato monumental. (...) El actual período de los "relieves" nos conduce hacia verdaderas construcciones que participan del carácter de una obra tridimensional. Junto al volumen natural y la estructura plástica, se incorporan ricas grafías o variados "collages". Entonces, además del valor pictórico, las formas adquieren dimensiones esculturales con el juego típico de luces y sombras (Ulloa, 1979, pp. 142-143).

A pesar de que se consideran tres etapas en la labor plástica abstracta, para el estudio de la última percepción pictórica, en el trabajo de la artista, se observa como prioridad el período de la máquina. Esta es una serie de pinturas dentro de las cuales se encuentra Supervivencia, obra con la cual participó en la I Bienal Centroamericana de Pintura -cuando se estableció el fin de la abstracción costarricense-. Asimismo, la obra es meramente pictórica y refleja el estado preciso de la última etapa de la pintura informalista en el país. Por otra parte, el periodo de los relieves se considera como obras tridimensionales que adquieren carácter escultural.

\footnotetext{
${ }^{1}$ La pintura informalista no debe ser entendida solo como un nombre para referir a la pintura abstracta, sino que esta debe ser asimilada como una variación contextual que plantea una ausencia de la forma: "Se intentó también desarrollar una teoría que situase la abstracción europea sobre las mismas bases del expresionismo abstracto americano. Muchos críticos usaron el término «arte informal» para indicar que la pintura ya había abrazado la idea de la ausencia de formas como una deliberada contraposición a la rigidez del movimiento moderno de preguerra" (Lucie-Smith, 1983, p. 109).
} 
En cuanto al estilo de la obra no-figurativa de la artista, el estudioso David Ulloa comenta la obra de Lola Fernández al referirse a sus composiciones abstractas, en las cuales explora el informalismo; de igual manera, habla de sus estudios en Asia y el conocimiento que esto aporta a su obra, volviéndola más rica e implementando, en su conocimiento occidental, técnicas como el estarcido (stencil):

Agrupa obras de la década de los 60 y explora el estilo llamado "abstracción informal". En 1961 Fernández obtiene una beca de la UNESCO para realizar estudios de pintura en Asia. Para este grupo de obras la influencia del arte japonés sobre el estilo de la costarricense es evidente en la distribución del espacio y en el uso de técnicas como la "veladura" o la superposición de capas. También se incorpora el uso del "stencil" o plantilla, técnica que se seguirá haciendo presente durante la obra de la artista (Ulloa, 2012, párr. 8).

Por las razones presentadas anteriormente, se estima la obra de Lola Fernández dentro del estilo abstracto informalista. Se considera para esto su periodo pictórico de la serie La máquina, debido a que esta se presenta meramente como pintura. A su vez, esta es relevante tanto por su nivel técnico, como por la importancia de su participación en la I Bienal Centroamericana de Pintura, con la obra Supervivencia.

\section{Acercamiento teórico-metodológico: semiótica y arte abstracto}

Para efectos del estudio de la obra de Lola Fernández, se propone un análisis semiótico basado en tres niveles correspondientes al significado de los signos: sintáctico, semántico y pragmático. El nivel sintáctico pretende analiza las relaciones entre los signos, es decir estudiando las unidades básicas de sentido. Por otra parte, al encontrar sentido a la relación de signos en las pinturas, se trabaja el segundo nivel, el semántico. Este es de suma relevancia para el estudio, pues no solo brinda comprensión al análisis semiológico sino que, a su vez, es el que abre la posibilidad al estudio meramente de la obra:

Este nivel semántico nos es ofrecido de modo implícito por el texto mismo, en la medida en que la selección de signos, su combinación, etc. constituye un sistema de creencias acerca de la realidad que puede estar o no en contradicción con lo que explícitamente el autor asuma como suyo, pero que es, en definitiva, el campo que nos interesa para el análisis. Ya hemos dicho y repetido con anterioridad que no importa tanto lo que un artista diga que quiere decir o hacer cuanto lo que realmente dice o hace (Talens, 1999, p. 54). 
De esta manera, el nivel semántico concierne a la proporción entre la interpretación de la obra y su correspondencia con la realidad denotada en las representaciones (o sea, con la obras mismas). Es decir, la suma de significantes y significados, al proporcionar un sentido coherente con la realidad, constituye este segundo nivel del estudio de la obra pictórica, sin importar las connotaciones que el artista de tal obra haya pretendido establecer.

Finalmente, el análisis de la pintura, desde su perspectiva sintáctica y semántica, posibilita el entendimiento sígnico de las representaciones y, a su vez, brinda la capacidad de contrastar las manifestaciones pictóricas con su realidad sociocultural de los años setenta en Costa Rica. Esta facultad de contextualizar la obra se presenta como la tercera fase del análisis semiológico, este es el nivel pragmático: "Dentro de este nivel se integran por una parte aquellos elementos que remiten a la relación autor/obra y a la correspondiente obra/lector, y por otra la referida al lugar de inserción de ambos, como sujetos de una práctica significante, dentro del conjunto de prácticas que constituyen una formación social" (Talens, 1999, p. 47). En este sentido, la correspondencia de la obra con la realidad socio-cultural de la época a la cual pertenece es significativo, pues, permite establecer la función de la obra como texto artístico portador de sentido y, así, determinar las características fundamentales de las obras para contrastar las variantes estéticas acogidas entre estas.

Para obtener un análisis semiótico de la obra Supervivencia como informalismo es necesario, inicialmente, establecer el concepto de abstracción. En este sentido, en cuanto a la relación constructivista del abstraccionismo, Ruhrberg y Honnef explican cómo toman una posición diversa al suprematismo, permitiendo entender la relación entre ambos términos a partir del aporte que realizan a la concepción de arte abstracto: "Tatlin fue el fundador del constructivismo, un movimiento, en comparación con el suprematismo, mucho más mundano y orientado hacia la tecnología y sus aplicaciones. Los cuadros abstractos y mecánicos y los relieves hechos de vidrio, madera, metal y hormigón de Tatlin, Rodchenko, Vasily Ermilov y muchos otros [...] también se puede remontar al constructivismo" (2005, p. 165). De esta manera, se postula la mecanización y tecnologización del arte abstracto y su aporte constructivista, por medio de Tatlin. 
Por otra parte, el término abstracción puede ser conceptualizado como nofiguración, en tanto que se observa como otra terminología para desarrollar la misma noción de arte abstracto. Para Ana Mercedes González Kreysa, en Historia general del arte (2007), explica esta situación:

Según los teóricos del arte no figurativo como el francés Michel Seuphor, un término como el de "abstracto" para adjudicárselo a una obra que no corresponde a la imitación de la realidad es incorrecto porque, ciertamente, toda obra de arte es una "abstracción de la realidad" al ser una recreación no necesariamente fiel de lo imitado del medio natural. De ahí que el término más adecuado para designar el arte no figurativo sería precisamente este último o de arte no-objetual. Pese a ésto, a fuerza de la costumbre convencionalmente se conoce a este tipo de manifestación como arte abstracto (p. 123).

Para Nicola Abbagnano, en su Diccionario de filosofía, el concepto de abstracción es entendido como: "Operación por la cual una cosa es elegida como objeto de percepción, atención, observación, consideración, investigación, estudio, etc., y aislada de otras cosas con las cuales se encuentra en una relación cualquiera" (1974, p. 20). Con esto se puede entender la abstracción en cuanto a su relación cognoscitiva, en tanto se vincula con procesos subjetivos y del desarrollo del pensamiento. Sin embargo, el estudioso continúa ampliando el término abstracto a través de intelectuales como Kant, Aristóteles, Santo Tomas, Locke, entre otros, estableciendo una perspectiva según la cual:

\footnotetext{
Tales análisis no niegan, sin embargo, la A., sino más bien su noción psicológica, en favor del concepto lógico-simbólico de ella. La A. no es el acto mediante el cual el espíritu piensa ciertas ideas separadamente de otras; es más bien la función simbólica de determinadas representaciones particulares (Abbagnano, 1974, p. 21).
}

En este sentido, Abbagnano no niega la relación meramente cognitiva de la abstracción como proceso del pensamiento, sino que le agrega rasgos sígnicos al acto de abstraer, llevándolo al plano de la representación, y proponiendo con esto una carga referencial-simbólica para la abstracción alejada de los convencionalismos de la abstracción como a-referencial.

De tal manera, Nicola Abbagnano propone la abstracción como un proceso mental a través del cual se vinculan símbolos de ciertas representaciones, librando a la abstracción de la a-referencialidad y proponiendo en esta una función sígnica. 
Por lo tanto, se comprenden algunas formas de designar el constructo teóricoconceptual de arte abstracto o abstracción. En consecuencia, es necesario asimilar el concepto de arte abstracto como no-figuración, arte no-objetual o abstraccionismo, como referente conceptual del estudio semiótico. Se empleará el término no-figuración como imagen de la realidad visual no-referencialidad inmediata y por su relación con la obra pictórica; asimismo, se preferirá el uso del término arte abstracto por ser un convencionalismo, como revela González Kreysa (2007).

\section{Contexto socio-histórico del fin de la pintura no-figurativa: I Bienal Centroamericana de Pintura}

La I Bienal Centroamericana de Pintura fue un evento convocado por el Consejo Superior Universitario Centroamericano (CSUCA) en 1971, con el propósito de unificar a Centroamérica, pues el panorama general era de violencia y crisis. En general, es un contexto socio-cultural y político convulso en el que se enmarca el fin de la abstracción costarricense:

\footnotetext{
Por lo tanto, la década del setenta fue un período en que la tensión política se mantuvo, en sus inicios se agudizó la crisis en el Cono Sur: Chile, Uruguay y Argentina. En Centroamérica, debido al triunfo de la insurrección sandinista en 1979 y a la ampliación de las posibilidades de una victoria militar de las fuerzas guerrilleras -en especial del FMLN en El Salvador-, se creyó posible una transformación radical, la cual se evidenció en el discurso político de la izquierda centroamericana, centrado en la idea de que la revolución era la salida a una herencia de violencia, autoritarismo y desigualdad (Barzuna, 2005, p. 24).
}

Dentro de este contexto, en la I Bienal Centroamericana de Pintura la obra ganadora fue Guatebala del artista guatemalteco Luis Díaz: "Este artista concibió un tríptico en metal remachado con tres formas losángicas secuenciales, sintético, y de estilo próximo a la señalética y a la secuencia del cómic; la obra presenta una armadura antigua que es acribillada de balas, desintegrándose; clara muestra de la situación guatemalteca y centroamericana que prevalecía por aquellos años" (Montero, 2012, p. 87). La obra de Díaz no solo es claro ejemplo de la situación que vivía Centroamérica a nivel político y social en ese momento, sino que es manifestación de la tendencia en la que estaba incurriendo, a nivel cultural, el arte de la región. No era manifestación nofigurativa como se había dado en el continente europeo, sino una nueva propuesta de carácter figurativo, que se proponía como una figuración con un fuerte sentido crítico de la situación centroamericana en el contexto de la época. 
Dentro de los motivos por los cuales la obra guatemalteca consiguió el primer lugar, se determinó su representación temática, clara muestra de los sucesos acontecidos en dicha nación: "Es importante explicar a los lectores que las condiciones de Centroamérica eran distintas y el militarismo dominaba aún [...] No es de extrañar que entre las temáticas de la escuela guatemalteca, el militarismo y los desaparecidos sean temas recurrentes y que caractericen al arte latinoamericano en esa época" (Montero, 2012, p. 86). Este motivo tuvo gran peso para que el arte costarricense no haya obtenido ningún tipo de distinción; no solo porque Costa Rica se mantenía al margen de las empresas militares, sino por la percepción que se generó del arte costarricense como influenciado por una práctica artística foránea.

Según la historiadora del arte Eugenia Zavaleta, parte del porqué del veredicto quedó aclarado al día siguiente de inaugurado el certamen en la Biblioteca Nacional, cuando se efectúa una mesa redonda sobre la pintura centroamericana. Zavaleta explica: "La crítica de arte Marta Traba manifestó que el arte de vanguardia latinoamericana había dejado de comunicar porque, al incorporar un lenguaje que no correspondía con su propia crisis sino con la norteamericana, se había convertido en una imitación del arte captado, a través de los medios de comunicación colectivos, de dicha sociedad de consumo" (1994, p. 155). De esta manera, se comprende la perspectiva del jurado y el motivo por el cual consideraron algunas de las obras costarricenses, sobre todo las de carácter no-figurativo, como no merecedoras de reconocimiento. Como afirma el historiador del arte Guillermo Montero, respecto al veredicto de esta Bienal y la circunspección que ha tenido a nivel local con el tiempo: "La negativa de conceder un premio a Costa Rica ha sido interpretado con los años, como una reacción contra la pintura no figurativa" (2012, p. 87). Esto no se debe únicamente al hecho irrefutable de que en Costa Rica no se podían representar fuertes acontecimientos político-sociales, sino por la misma tendencia de los artistas, tras este resultado, de abandonar toda manifestación no-figurativa en la pintura del país.

El resultado final del jurado, el cual consistió en la abstención de otorgar una mención a los artistas costarricenses que participaron, no solo se asumió como una reacción contra el arte no-figurativo nacional y sus carencias de relación temática con los conflictos centroamericanos de los setenta, sino, también se consideró como una predisposición positiva hacia la tendencia del arte neofigurativo en Latinoamérica. Así, la predilección del jurado por esta última es evidencia importante del impulso que tendría: 


\begin{abstract}
Al finalizar la década de los años sesentas, el pintor mexicano José Luis Cuevas visitaba San José. Los estudiantes de Bellas Artes le conocían y también los artistas que en futuro participarán en la Bienal, pero en 1971 regresaría como jurado junto a Marta Traba; ellos constituirían el impulso más fuerte de retorno a la figuración, y el frente de oposición a las tendencias no figurativas que habían permitido penetrar el arte de América Latina. Marta Traba se convirtió, con los años, en la promotora de la neofiguración, sustentada en lo que llamaría "Los cuatro monstruos cardinales", dando énfasis a Francis Bacon (Montero, 2012, p. 86).
\end{abstract}

Al observar la reacción de los artistas costarricenses luego del dictamen del jurado, donde se evidenció una inclinación por la tendencia figurativa y neofigurativa, se comprende por qué el arte nacional abandonó la expresión nofigurativa, a la vez que se volvió hacia una manifestación pictórica más figurativa.

\title{
IV. Análisis semiótico-pictórico del informalismo costarricense con "Supervivencia" (1971)
}

Con de la obra Supervivencia (1971) de la artista costarricense Lola Fernández, se establecerá el fin de la pintura no-figurativa de carácter informalista en Costa Rica. Esto es necesario para comprender las particularidades de uno de los estilos pictóricos que enmarcan la no-figuración costarricense.

Para interpretar correctamente la obra dentro de este movimiento, es necesario comprender cómo se determina el informalismo en el contexto mundial, las características más específicas con que se ha definido este, así como un pequeño proceso histórico:

\footnotetext{
Paralelamente en Europa se desarrollan tendencias similares a las surgidas en Estados Unidos, que ha sido denominado como Informalismo. Dentro de este movimiento encontramos toda una variedad de propuestas plásticas que irán desde la abstracción de carácter caligráfico, muy emparentada con el action paiting (Fig. 5.9) hasta un Expresionismo lírico-abstracto basado en formas fluidas e irregulares, cuya constante es el valor intrínseco y evocador del color. Otra vertiente se encuentra presente por la pintura matérica (...) (González-Kreyza, 2007, p. 176).
}

Como se puede observar, el informalismo se debe interpretar como un estilo muy variado, dentro del cual se puede establecer la obra de Supervivencia (1971); es decir, este movimiento plástico se puede interpretar como un nombre más para decir abstracción o no-figuración. Sin embargo, hay que considerar al informalismo como una tendencia variada, la cual permite gran cantidad de técnicas e implementación de formas artística que posibilita incluso la incorporación matérica en las obras. 
En este sentido, del acercamiento de la obra no-figurativa al trabajo de diversas tendencias, como el action paiting y la pintura matérica, se puede interpretar como una forma de establecer o clasificar la obra como no-figurativa. Esto lo determina la estudiosa del arte abstracto, Aurora Alcaide, cuando habla de una Clasificación de la pintura abstracta en función de sus características formales; en esta determina el carácter de un trabajo matérico: "(...) Abstracción Matérica es la contundente presencia de las texturas táctiles en la composición, las cuáles no siempre son el resultado de la abundante aplicación de materia pictórica sobre la superficie del cuadro, sino también de la incorporación de distintos materiales al mismo, como papel, maderas, cartón, polvo de mármol etc." (2010, p. 11).

En este sentido, se puede considerar Supervivencia (1971) dentro del informalismo gracias al variado trabajo técnico, al incorporar diversos materiales dentro de la pintura (obra matérica). Con esto, la pintura no solo es ruptura en el sentido académico para la Costa Rica de los sesentas y setentas, sino que se plantea como novedosa al implementar nuevas técnicas plásticas en el país, abriendo nuevas perspectivas en la visión de los artistas nacionales.

El uso de diversos materiales va aunado a la implementación de nuevas técnicas pictóricas, como lo establece María Alejandra Triana al referirse al trabajo pictórico de la artista: "Desde mediados de los años 60 hasta principios de los 80, Fernández decidió experimentar con una mayor diversidad de recursos técnicos, como el collage, el estarcido, el relieve, la transferencia química de imágenes y el arte textil. Todo ello le permitió desplegar series temáticas -algo usual en toda su producción- que visualmente resultaron muy distintas entre sí" (2012, párr. 21). De esta manera, Triana proyecta la variedad técnica de la artista y, a su vez, indica una particularidad de la obra, que hasta el momento no había sido implementada. Se trata del uso de series. Las series temáticas posibilitan la creación de obras en torno a una misma idea y desarrollo plástico.

Como parte de estas series, se encuentra una de gran significación dentro de su periodo abstracto, La máquina, donde se halla la obra Supervivencia (1971). Esta es interpretada por Guillermo Montero como:

La pintura de Lola constituye una imagen explosiva. El rojo, color reiterado en su obra desde los años sesentas y asociado a la violencia, explota ante el espectador, no sin sutilezas; integrando todo tipo de información de la cultura contemporánea, denunciando el kitsch local y generando un espacio difícil de olvidar; así, el título de una de sus obras es sugerente: Supervivencia (2012, p. 88). 
En consecuencia, es significativo apreciar como Montero se deja guiar por el paratexto de la obra, proponiéndolo como sugerente y relacionándolo con significados como violencia. Al estudiar el título de la obra se puede establecer Supervivencia como: "Acción y efecto de sobrevivir" (Real Academia de la Lengua Española, 2001, p. 1433). En este sentido, sobre esa acción de sobrevivir ¿cómo se puede interpretar? y ¿a qué se debe sobrevivir?

Para la estudiosa del arte Eugenia Zavaleta, la obra habla del caos en el cual vive el hombre, llegando a connotar, incluso, ideas de muerte y destrucción:

En Supervivencia, Fernández creó un sutil eje vertical y otro horizontal, con el que definió un punto áureo, a partir del cual una explosión de imágenes y formas traducen el caos que rodea al hombre. Esa amenazante conmoción es resaltada aún más con el predominio del rojo y el negro, manipulando sus connotaciones de fuego, destrucción y muerte. La artista se valió, sobre todo, de recursos puramente pictóricos para crear dicho ambiente, pero también introdujo la figura, consistente en un sutil collage de escenas, como por ejemplo, de guerra y de teatro (1994, p. 77).

Zavaleta no solo define la obra como esa supervivencia del hombre ante el caos en el que vive, sino que lo relaciona con la idea de guerra y sobrevivencia a la muerte. Esto al incorporar imágenes figurativas por medio de la técnica del collage. Asimismo, relaciona sígnicamente estas figuraciones y este caos plástico con el uso de los colores predominantes: rojo y negro. En este sentido, al estudiarlos se puede establecer, por ejemplo en el caso del negro, que:

"Simbólicamente es más frecuentemente entendido en su aspecto frío, negativo. Contracolor de todo color, está asociado a las tinieblas primordiales, a la indiferencia original. En este sentido recuerda la significación del blanco neutro, del blanco vacío, y sirve de soporte a representaciones simbólicas análogas, tales como los caballos de la muerte, tanto blanco como negros" (Chevalier, 2009, p. 747).

La simbología del negro puede ser asociada con la del rojo el cual representa gran cantidad de significados, todos relacionados con vida, fuego, guerra, energía, agresión, peligro, entre otros. Se tiene así, negro-muerte y rojo-vidaguerra; indiscutiblemente se presenta una dicotomía vida-muerte, donde la presencia de la guerra parece fundamental. Esto, en asociación directa con el paratexto, permite interpretar esa Sobrevivencia como juego entre vida y muerte. 
Por otra parte, al estudiar las figuras que sutilmente sobresalen en el caos plástico de manchas y pinceladas, es posible observar una mujer que se abraza, unos militares sosteniendo sus rifles, unos bailarines, así como una pareja con un niño y un mono de la mano. Estas imágenes no solo representan -en síindividualmente, sino que, en conjunto, son parte de esa aglomeración de manchas, pinceladas, letras sueltas y figuras, connotando, como lo estableció Zavaleta, un caos. Estas figuras visibles en una obra no-figurativa, funcionan como isotopías discursivas que redundan en un mismo tema; se puede establecer como un paralelismo con el mundo contemporáneo: publicidad, ciencia, política, cultura y sociedad, mezclados y aglomerados. Es decir, en sí, cada imagen no dice nada; es en su conjunto y aglomeración dentro de la pintura que adquieren sentido, asociado a ese caos de la sociedad contemporánea.

En cuanto al trabajo plástico como proceso pictórico-conceptual, en Supervivencia (1971) se reconoce el hecho de que el trabajo carece de planificación. En este sentido, responde a las particularidades del informalismo, en el cual no se plantean diseños o propuestas. La obra surge inmediatamente de la idea, y el trabajo plástico se resuelve en el propio acto de pintar (es necesario conocer la referencia de la artista, no como su interpretación de la pintura, sino sobre su proceso pictórico, esto para poder determinar con precisión la obra Supervivencia dentro de estilo Informalista):

\footnotetext{
P: ¿Y cómo le surgen las ideas?

L: No sé, me vienen y las voy madurando, no boceteo, con esa idea yo me lanzo a hacer series -yo fui de las primeras en hacer series, porque antes no se usaba-, me basaba en una idea central que siempre tenía una razón de ser. No he hecho nada gratuito, todo tiene una razón de ser (En: Aguilar y Báez, 2013, párr. 10).
}

La obra pictórica, al estar realizada en directo sobre el bastidor, se propone como una obra completamente informalista, sobre todo si se contempla el uso de diversas técnicas (collage y estarcido) y la implementación de nuevos materiales; igualmente, esto se da por la incorporación de lo que se considera una constante en la obra de Fernández: "Es una constante mía, la de los chorreos" (En: Zúñiga, 2013, párr. 14). Sin embargo, aunque la pintura es estimada como no-figuración, se debe tener presente que: "En realidad, la pintora, a lo largo de su carrera artística, se ha desenvuelto tanto dentro de la figuración como dentro de la abstracción" (Zavaleta, 1994, p. 77). Esto no solo es relevante para comprender que ambos procesos se daban al unísono, sino 
para entender que la pintura abstracta muchas veces contemplaba la figura como parte del trabajo.

Es en este aspecto donde se hace relevante considerar el vínculo entre la nofiguración informalista y la referencia o a-referencialidad en la pintura. Para esto, es conveniente estudiar lo que Alcaide (2010) considera como la Taxonomía de los cuadros abstractos aplicando el criterio de su grado de realidad; esto lo consigue mediante la clasificación de las obras no-figurativas. En este sentido, la estudiosa presenta: 2.1.3. Abstracción de 3er Grado o Pseudo-Abstracción, dentro del cual se considera posible clasificar Supervivencia (1971); este criterio establece que: "La Abstracción de 3er grado o Pseudo-abstracción se caracteriza por sus referencias formales y conceptuales a la realidad. No obstante, esta interpretación del mundo natural no se realiza de una manera literal, sino sutil y metafórica, y a través del filtro de la subjetividad del artista" (2010, p. 19). De tal manera, la obra Supervivencia se presenta como la realidad subjetivada; es una metáfora visual. Pero, finalmente, la metáfora de la pintura es interpretada por el espectador, siendo este quien denota la carga simbólica en esta.

Para Alcaide (2010), esta tipología de obras Abstracción de 3er Grado o PseudoAbstracción, se puede dividir en tres subgrupos, dentro de los cuales el tercero (tipo B) se cavila como el más próximo al trabajo de la pintura en estudio, pues establece que:

\footnotetext{
Obras que, valiéndose de determinadas técnicas, como la fotografía, el collage o las trasferencias, incorporan en su superficie compositiva las formas abstractas que existen en la naturaleza, bien naturales o artificiales, descontextualizadas y/o ampliadas (muchas de estas formas proceden de organismos o estructuras microscópicos que a simple vista no remiten a nada de la realidad)" (2010, p. 20).
}

Tal y como se propone aquí, las obras no-figurativas pueden incorporar en sí la figuración sin dejar de ser consideradas abstractas. Por este motivo Supervivencia (1971), a pesar de sus referentes visuales reconocibles, sigue siendo no-figuración. No solo es esto lo que la clasifica dentro de esta tipología que establece Alcaide (2010) (para las obras abstractas), sino que, la incorporación de otras técnicas matéricas como el collage logra integrar la figuración como no-figuración. 
Sin embargo, lo anterior no quiere decir que la obra se considere completamente a-referencial, pues la referencialidad de una obra (como ya se ha discutido anteriormente) no depende de la figuración o no-figuración; así, toda obra abstracta puede ser referente del mundo visual reconocible. Esto se puede distinguir en la pintura, a través de la relación paratexto-imagen. En este sentido, se puede entender la obra de pintura como referente del mundo visual, en tanto que representa algo; un algo que puede estar sugerido por la guía del paratexto y que, sobre todo, está determinado por la subjetividad y se concreta en un determinado contexto.

Siguiendo la idea de la no-figuración como referencial y, asimismo, como una mezcla entre figuración y abstracción, se puede estudiar lo que Alcaide (2010) determina como Grado de realismo del cuadro. Esto lo plantea al diferenciar entre la no-figuración como un camino que se aleja del naturalismo, y un trabajo que mixtura la figuración y abstracción:

Esta tendencia innata a mezclar figuración y abstracción justifica el hecho de que, aunque muchos artistas abstractos hayan tomado el camino del alejamiento total de la naturaleza, otros hayan optado por fórmulas mixtas que a continuación se estudiarán, y que no por ello, por ser "impuras", dejan de ser menos válidas. Por lo tanto, cobra sentido cuestionarse acerca del grado de realismo cuando se contempla un cuadro abstracto (Alcaide, 2010, p. 15).

Así, se puede estudiar la pintura Supervivencia (1971) como una obra que mezcla figuración y no-figuración sin llegar a perder su sentido de obra abstracta. Como anteriormente se mencionó, los trabajos con tales características son clasificados por Alcaide (2010) como Abstracción de 3er Grado o Pseudo-Abstracción, pues este tipo de clasificación se logra al subdividir los tipos de obras. En el caso de Supervivencia, al estar realizada con óleo y collage (técnica mixta), puede ser clasificada en la categoría B; así las obras abstractas pueden incorporar la figuración sin perder su sentido de obras abstractas.

De esta manera, en Supervivencia (1971) es importante contemplar las figuras que se incorporan no solo como representaciones, sino como un todo compositivo donde se entremezclan con los chorretes, las manchas y las pinceladas, para interpretar la obra como representación subjetiva, al igual que para interpretar su relación contextual. 
En cuanto a la contemplación de la obra en su totalidad compositiva, y no solo en la individualidad de las figuras usadas, es necesario considerar el trabajo como una sola imagen; es decir, estudiar qué quiere decir la pintura en su totalidad, como representación subjetiva. Para José Gómez Sicre, Crítico de Arte y Director del Museo de Arte Contemporáneo de la América Latina Washington D.C., el trabajo de Fernández mantiene una relación entre color, elementos plásticos y figuras de manera que genera una percepción global de la imagen, interpretada en su concordancia espacio-temporal:

Es decir, aunque se proponga elaborar la realidad, lo plástico se sobrepone, desentendiéndose del mundo de donde emergió. Esa ambivalencia da su sello definitivo a la personalidad de esta creadora. Ejemplo preciso es la serie que titula La Máquina, en la que agrupa elementos disímiles, tomados de la realidad, con que produce un todo abstracto, a veces insertando figuras recortadas y pegadas en hábil collage. Generalmente, vuelve a predominar en estas masas de aspiración monumental el rojo hábilmente mezclado con un gris acero. Esta asociación cromática se nos ofrece como advertencia dramática o crítica sobre el destino confuso de la humanidad (En: Museo de Arte Costarricense, 1974, p. 7).

De esta manera, Gómez establece, en los trabajos de la serie La Máquina -a los cuales pertenece Supervivencia-, una ambivalencia entre figura y abstracción, donde predomina la no-figuración; así, al relacionarse con los cromemas, esta (la obra) propone establecer ese caos que rodea al hombre del que hablaba Zavaleta y que, según Gómez, es connotación del confuso destino de la humanidad.

Por lo tanto, las figuras como recortes de un collage en Supervivencia se pierden dentro del colorido de la obra entre manchas y pinceladas, generando una sola imagen abstracta. Sin embargo, esto no quiere decir que la obra no-figurativa no represente, como se había mencionado anteriormente. Toda obra abstracta no puede ser a-referencial. En los casos de las obras no-figurativas de la pintura costarricense, es necesario considerar el todo de la composición para reconocer esa característica representacional. Así como lo inquiere el periodista Randall Zúñiga, al referirse al trabajo pictórico de la artista:

Aunque lo mencione, Lola rehúye de la dicotomía entre arte abstracto y figurativo. Arguye que todo arte resulta figurativo. De ahí que la composición de la mayoría de su obra, con una figura redonda en la parte superior y una figura rectangular hacia el centro -a veces la cabeza y el torso de un retrato directo, a veces la abstracción de un paisaje- unifique buena parte de la exhibición (2013, párr. 22). 
De esta manera, Supervivencia (1971) 'puede ser considerada como un paisaje abstracto, donde entre el colorido y las manchas reconocemos formas y figuras humanas. Por otra parte, es necesario contemplar qué quiere decir esta representación plástica. En este sentido, es necesario estimar que una obra informalista se ve referenciada por su contexto. Como propone la estudiosa Bélgica Rodríguez, cuando se refiere a la pintura de la artista como una dicotomía entre una realidad subjetiva y una objetiva: "La suya es en parte una realidad subjetiva que proviene de sus sueños, de sus fantasmas y de sus preocupaciones, así como también de una realidad objetiva, cuya procedencia está en su entorno y las señales que este le provee (Galería Valanti, 1998, p. 6). Así, la pintura se distingue como una representación más del contexto cultural de Costa Rica en su época.

Al revisar en qué forma la obra representa y simboliza (semántica de la pintura), se puede relacionar con el estudio de Alcaide (2010), cuando propone que un cuadro puede tener diferentes funciones; una de sus funciones más comunes es la transmisión de una máxima moral o sea de una idea. Dentro de estas determina: "Establecer conexiones entre el arte y la tecnología mediante la creación de imágenes que son fruto del híbrido pintura-fotografía [...] o de la aplicación de la cibernética al arte" (Alcaide, 2010, p. 26). Eso permite establecer en la pintura Supervivencia (1971) ese vínculo entre pintura-fotografía, como esa conexión entre arte y tecnología, la cual se podría valorar como uno de los motivos en la obra.

Cuando se estudia la pintura, se pueden observar varios elementos que vienen a confirmar esa correspondencia entre arte y tecnología del que habla Alcaide (2010), como: la mixtura de técnicas como el óleo y el collage fotográfico, la combinación entre manchas, texturas y letras estarcidas o, el uso del color rojizo y un gris acero. Esta ambivalencia en Supervivencia es, para Zavaleta (1994), el referente de la amenaza de la máquina, y considera que en esta se representa ese entorno opresivo de la tecnologización:

Ese ambiente saturado y asfixiante lo transmite en el cuadro Supervivencia [...], incorporando algunas letras que simbolizan los rótulos de la ciudad. Asimismo empleó desechos de máquinas, a modo de pastillas, para imprimir patrones de formas geométricas, algunas de las cuales recuerdan "...la omnipresente computadora, simbolizada por unidades de memoria organizada de manera repetitiva..." Estas impresiones llevan implícita la amenaza que significa el poder de la máquina, capaz de devorar al hombre mismo. Por ejemplo, Fernández considera que muchos de los problemas de Latinoamérica son debido al abrupto paso de la carreta al avión, lo cual no ha permitido asimilar adecuadamente la tecnología (1994, p. 76). 
De esta manera, las diversas imágenes fotográficas implementadas con el collage, los colores -rojo, negro y gris acero-, los estarcidos de texturas y letras, son isotopías discursivas que giran en torno a un denominador común; así, se interpreta la pintura como esa representación simbólica del caos y ruido (visual) de la revolución tecnológica. Esto, en relación directa con el paratexto, se puede comprender como la supervivencia del ser humano en medio de la vida cotidiana tecnologizada.

Ese caos que sugiere la obra, -por la mezcla de imágenes, manchas y letras-, es para muchos no solo representación del avance tecnológico, sino, una muestra de la reacción de la misma sociedad ante el despliegue de la modernidad. Como sugiere Ricardo Ulloa, al referirse a la obra: "De otra parte, en Supervivencia la superficie acribillada con verdaderos estampados donde los "recortes", fusionados con los pigmentos, sugieren el diálogo social de nuestra era, con caos y su belleza" (1979, p. 143). Así, se establece en la obra un diálogo social que contempla caos y belleza; es la pintura retratando la realidad y fusionando todo dentro de su armonía de color y composición.

Por otra parte, la implementación de nuevas técnicas en la pintura, como el collage, los estarcidos y el uso de esténciles, tienen su fundamento en los viajes realizados al extranjero. Como expone Randall Zúñiga: "La influencia europea luego tendría su contraparte -o complemento- gracias a un nuevo viaje, ahora por África y Asia, y de a poco empezó a sumar, también, collages y esténcils" (2013, párr. 31). Esta influencia del extranjero no solo enriqueció el trabajo pictórico de la artista (se considera pertinente hacer este tipo de referencias, pues repercuten directamente sobre la pintura en estudio), sino que abrió todo un panorama plástico para el arte costarricense. Sin embargo, esta implementación iba a tener, con el tiempo, un costo para la obra.

Es significativo estimar que Supervivencia es una de las pinturas con las cuales Lola Fernández participó en la Primera Bienal Centroamericana de Pintura, junto con Evolución (1971) y La Respuesta (1971). La participación de la obra en esta bienal tiene relevancia a nivel de la plástica nacional, no solo debido al veredicto en esta, sino por considerarse un síntoma dentro de las causas que llevaron al arte abstracto costarricense a su fin. 
Como anteriormente se ha referido sobre el veredicto de la Primera Bienal Centroamericana de Pintura, es necesario agregar que el jurado de esta primera bienal -que estaba compuesto por: Marta Traba (Argentina), José Luis Cuevas (México), Fernando de Szyszlo (Perú), Armando Morales (Nicaragua) y Oswaldo Guayasamín (Ecuador)-, inicialmente sostuvo que la causa por la cual declararon desierto el Premio Nacional de Costa Rica, se debía a un empleo excesivo de algunas técnicas: "(...) la participación de este país a pesar de presentar un aceptable nivel técnico en los casos de Lola Fernández, Rafael Fernández y Jorge Manuel Vargas, tiene un empleo superficial de recursos ya empobrecidos por el uso excesivo (collage de fotografías, pistola de aire, frotagge, etc.)" (Zavaleta, 1994, p. 155). Sin embargo, el trabajo técnico no parecía justificar la resolución del jurado, generando agitación en el ambiente nacional.

Ante esto, como manifiesta la historiadora del arte Eugenia Zavaleta, al día siguiente, el jurado aclaró el motivo de su decisión, dando como razones el hecho de que el arte latinoamericano, al asirse de nuevos lenguajes importados, dejaba de comunicar su propia realidad:

La crítica de arte Marta Traba manifestó que el arte de vanguardia latinoamericano había dejado de comunicar porque, al incorporar un lenguaje que no correspondía con su propia crisis sino con la norteamericana, se había convertido en una imitación del arte captado, a través de los medios de consumo. Traba consideraba que los países latinoamericanos estaban viviendo un periodo revolucionario; por lo tanto, la pintura debía de unírseles, haciendo su propia revolución y recuperando su lenguaje para así readquirir su capacidad de comunicación con el público. (1994, p. 155).

De esta manera, el jurado no solo consideraba poco pertinente el arte costarricense a nivel técnico, sino que lo alejaba de la realidad latinoamericana, sobrevalorándolo de imitativo y como falto de relación con el contexto.

Como se ha mencionado anteriormente, la realidad del país no era igual que la del resto de la región centroamericana. Sin embargo, se valoraba desde los mismos parámetros que los países vecinos. Como lo indica la historiadora del arte Ericka Solano, sobre la opinión del artista costarricense José Miguel Rojas, al referirse a la decisión del jurado en dicha bienal, quien debate la postura de que la no-figuración no aporta al contexto del país:

En la opinión de Rojas el jurado al esperar de Costa Rica una obra forzosamente política se colocó en una posición dogmática y politizada, generalizando la situación centroamericana juzgó que la representación costarricense estaba descontextualizada del drama centroamericano, sin darse cuenta de que las obras eran un producto vinculado con su propia realidad (Solano, 2014, p. 230). 
En el sentido que propone Rojas, la realidad política en el país era totalmente diferente a la centroamericana, lo cual era parte de las críticas del jurado en la I Bienal, al generalizar la contextualización de las obras costarricenses. Por otra parte, el país carecía de revolución política; sin embargo, en materia artística, la pintura no-figurativa venía a establecer su propia revolución con la ruptura ante el academicismo costarricense (revolución plástica) y su posterior aceptación dentro del medio. Esto, como manifiesta Rojas, significa que las obras eran un producto vinculado con su propia realidad.

Por otra parte, si se considera la pintura como una importación técnica, y ante una posible descontextualización con la realidad latinoamericana: "Traba criticaba en los artistas latinoamericanos, como Lola Fernández, que se vinculaban a las vanguardias europeas y estadounidenses" (En: Solano, 2014, p. 227); es necesario contemplar cuál es el problema de incorporar nuevos leguajes plásticos a la pintura nacional.

En este sentido, es posible explorar cómo el arte latinoamericano ha sido desdeñado por los europeos, al ser considerado como una copia. A esto se suma que críticos de la región, como Marta Traba, reafirmen tales discursos occidentales, sin priorizar en la relación global del arte latinoamericano. Es decir, el arte de la región se encuentra inmerso en una serie de influencias inevitables, de las cuales surge un arte local. Algo similar ha ocurrido con el arte europeo:

Como bien señala José Emilio Burrucúa fuimos acostumbrados al abordaje de las vanguardias del siglo XX, tomando los inicios desde Europa, y Europa lo hace con sus más grandes artistas vanguardistas. Sus fuentes - de originalidad, de rareza, de diferenciación - fueron los países llamados por ellos "exóticos", en aquel contexto histórico-social del Viejo Continente. Ejemplos reconocidos son Henri Matisse, Paul Gauguin, Pablo Picasso, entre otros. Aquellos artistas se interesaron por otras culturas, modificando su forma de ver a esas culturas, desprendiéndose de la mirada propia del pensamiento colonizador para aprender de ellas. Así Picasso posará su atención en las máscaras africanas, Matisse hará lo propio con las estampas japonesas (Selva, 2011, p. 3).

De esta manera, se puede observar como el arte europeo ha gozado de licencia para asimilar otras formas estéticas ajenas. No obstante, en el caso de Latinoamérica, el arte ha sido estigmatizado como mimético, tanto en lo técnico como a un nivel temático y contextual. Por este motivo, es posible valorar la obra Supervivencia, no como una copia del arte extranjero -como señala la crítica del arte Marta Traba, tras el veredicto de la I Bienal Centroamericana-, sino como una labor que tiene un valor a nivel local, como ruptura estética o revolución plástica que, implementando técnicas foráneas, logra un lenguaje propio dentro del contexto al que pertenece. 
Hay que considerar que esta revolución plástica -esa estética abstracta en la pintura-, fue iniciada en 1958 (junto con Manuel de la Cruz González y Felo García), cuando expone por primera vez en el Museo Nacional. Por lo tanto, en 1971, cuando se da la bienal, esta tendencia no-figurativa lleva más de una década de estarse ejecutando y genera un discurso desgastado. En este sentido, no se puede valorar únicamente el criterio de que el arte abstracto fuera o no contemplado como una labor oriunda o importada (como señala Traba), o de que a nivel técnico se manejara un empleo superficial de recursos ya empobrecidos por el uso excesivo (como determinó el jurado de dicha bienal). Es necesario comprender la I Bienal Centroamericana de Pintura como ese síntoma que determinó un discurso ya agotado para la época, el cual se manifestó a través del veredicto del jurado, la crítica de arte alrededor del tema, así como, por el mismo desuso de la tendencia por parte de los tres representantes del arte abstracto costarricense.

Por otra parte, la obra Supervivencia (1971), al igual que la I Bienal, se ubican en un contexto histórico costarricense particular, con características que derivan del devenir del arte nacional. Es necesario observar la época para establecer su relación con la obra y, así, determinar cómo es que se interpreta la conclusión del informalismo en Costa Rica.

Cuando la obra es presentada en la Bienal, Centroamérica se encontraba en procesos de industrialización, como asevera el historiador Iván Molina: "El universo comercial se transformó en dos fases. La primera, producto de la industrialización de Centroamérica, comprendió las décadas de 1960 y 1970, y se caracterizó porque la expansión del consumo, estimulado por una profesionalización creciente de la publicidad y por la televisión, fue mediatizada por la integración del istmo (...) (2007, p. 12). Esta situación de la región traería consecuencias para el país, tanto a nivel económico como cultural, y coincide temporalmente con el establecimiento de la plástica abstracta.

En Costa Rica, este despliegue industrial tiene sus inicios a mediados de la década de los sesenta, al unirse al resto del istmo. Esto traería, para el país, un desarrollo tecnológico, así como consecuencias económicas significativas: "El verdadero despegue de la industria ocurrió en 1963, cuando Costa Rica se unió al Mercado Común Centroamericano, el cual fue originalmente diseñado para integrar las estructuras productivas de la región y dotarlas de los beneficios de las economías de escala, al fomentar industria sustitutiva de importaciones" 
(Molina, 2005, p. 31). Al contemplar estos acontecimientos de la época, es factible establecer un vínculo inmediato con la pintura Supervivencia, en la cual se pretendía representar esa máquina como referente tecnológico, lo que Zavaleta (1994) considera la amenaza de la máquina.

Dentro de este contexto, es necesario reconocer por qué a esta apertura tecnológica se le consideraba amenazante, siendo incluso motivo para que Fernández titule su obra Supervivencia; a qué se refería esta supervivencia dentro de la serie La Máquina- en su contexto.

Para considerar la relación del paratexto de la obra con la realidad del país, es necesario estimar las consecuencias de la apertura industrial de mediados de los años sesenta, que se estarían haciendo visibles a inicios de los años setenta. Para Molina, ese auge industrial no significó un crecimiento para todo el país, sino que se focalizó en cierto sector:

\begin{abstract}
Como resultado de lo anterior, y del uso intensivo de la tecnología, el despegue industrial fracasó en generar abundante empleo. Los salarios de los que encontraron trabajo en ese sector ascendieron sólo un 10 por ciento ente 1962 y 1972, a pesar de que la tasa de crecimiento anual de las ganancias fue de un 19 por ciento en ese período (2005, p. 33).
\end{abstract}

De esta manera, es posible entrever por qué la obra se titula como Supervivencia, dentro de la serie La Máquina, pues este auge tecnológicoindustrial de su época no significó un aporte al mejoramiento de la situación económica del empleo costarricense, ni de su forma de subsistir.

Por otra parte, el desarrollo industrial tiene una contraparte en el ambiente urbano de la capital. Como explica Iván Molina, entre 1960 y 1980, se da la primera fase de expansión urbana, la cual tiene como consecuencia: "(...) a lo largo de las principales vías de acceso al casco josefino florecían una urbanización espontánea y desordenada, falta de todo tipo de planificación, en la que confluían viviendas con comercios, talleres y fábricas, un universo sin áreas verdes apropiadas, ruidoso y con el aire cada vez más contaminado" (2007, p. 4). Según la imagen de la ciudad de San José que expone el historiador, es fácil comprender como la pintura representa el caos que rodea al hombre -del que hablaba Eugenia Zavaleta-, o de ese confuso destino de la humanidad que identifica José Gómez Sicre en Supervivencia. La obra es, indiscutiblemente, un referente visual de la situación tanto temporal como espacial de la Costa Rica de 1971. 
Para finalizar, se puede interpretar Supervivencia como ese caos que desató el periodo industrial en el país; el desarrollo tecnológico, la falta de planificación urbana y la ausencia del crecimiento en el sector empleo, se manifiestan visualmente en la composición, a través de ese conglomerado de imágenes, texturas, letras, manchas y colores, que no solo reflejan La Máquina de la industria y la tecnología, sino que son referente de esa difícil labor de sobrevivir en medio del caos, ese confuso destino de la humanidad.

En cuanto a la labor pictórica posterior a la no-figuración de Fernández, se advierte un trabajo no solo figurativo, pues siempre trabajó la figuración al lado de la no-figuración -como advierte Eugenia Zavaleta-, sino una nueva figuración dentro del proceso de la pintura: "En la Serie La Máquina, aparecen ambas tendencias interactuando y esto, junto con la forma en que se manejó los elementos arriba analizados, crearon un nuevo lenguaje plástico que marcó el inicio de otra etapa en la producción artística de Lola Fernández" (Zavaleta, 1994, p. 77). En este sentido, se puede apreciar Supervivencia no solo como manifestación del último periodo de la pintura no-figurativa en el país, sino que, a su vez, es posible entrever en esta una posterior y novedosa figuración de la pintura de Costa Rica.

\section{Conclusiones}

La obra Supervivencia (1971), en tanto representante de la pintura no-figurativo costarricense, permite determinar las características plásticas y una semántica con la cual es posible observar la relación contextual entre pintura y cultura. En este sentido, el análisis semiótico de la obra reconoce las características con las cuales se llega al fin del periodo abstracto en la pintura del país.

La expresividad de esta pintura, una pincelada de factura más abierta, el uso de chorretes, así como la incorporación de nuevos materiales y técnicas (collage, estarcidos, transferencias, entre otros), definen su trabajo como informalista. Conjuntamente, se encuentra que la pintura no utilizaba ningún proceso de boceto y trabajaba directamente sobre el bastidor.

Asimismo, el uso del color, en Supervivencia (1971), refiere a una relación negativa (negro-muerte y rojo vida-guerra), connotando la obra con asociaciones violentas. Asimismo, al estudiar otros colores, como el rojizo y gris acero, se ha asociado a elementos mecánicos técnicos-industriales. Esto llega a 
ser sugerente al relacionarse con el título de la serie de obras La Máquina. De igual manera, la incorporación de imágenes dentro del trabajo, manifiesta en la obra una carga discursiva asociada a la contemporaneidad (política, ciencia, cultura y vida cotidiana). A través del vínculo: color, manchas, pinceladas e imágenes (letras, personas, maquina), se pueden apreciar denotaciones de caos y confusión; todo esto se consideran isotopías que giran en torno a un solo discurso, el de la modernidad, y la imposición del cambio tecnológico para la sociedad, trayendo con este caos y confusión.

Por otra parte, la participación de la pintura -Supervivencia- en la I Bienal Centroamericana, permite establecer lo siguiente. En primera instancia, a través del estudio del veredicto del jurado, se observan las críticas de arte surgidas por este suceso; en segundo lugar, también se visualiza el desuso del estilo por parte de los artistas no-figurativos, y cómo el estilo llegó a generar un discurso rupturista desgastado para la pintura costarricense. Esto significa que la Bienal era un síntoma más de lo que se gestaba en la plástica costarricense.

Supervivencia es un referente contextual costarricense para 1970, pues connota formas de percibir la situación socio-cultural. Esto a través de las particularidades en las manifestaciones sociales, económicas y culturales, las cuales se veían interpretadas en la obra no-figurativa Supervivencia.

La expansión del consumo de masas, estimulado por la publicidad y la televisión fue el resultado de que Costa Rica pasara de un modelo agroexportador a uno industrializado; esto, en parte, como consecuencia de la unión al Mercado Común Centroamericano. Este cambio económico en el país es, a su vez, signo de un cambio político y cultural, pues Costa Rica se encontraba en pleno capitalismo real, con la llamada globalización y la evidente modernidad instalada. Dichas transformaciones van a ser notorias en la pintura no-figurativa costarricense. Asimismo, Supervivencia personifica esa realidad costarricense ante las consecuencias de una industrialización malograda y su caótico devenir social y urbano, al incorporar figuras que sugieren la relación con la máquina y la tecnología.

Por lo tanto, es posible afirmar que la obra (Supervivencia) es referente visual del fin de la abstracción costarricense; asimismo, permite distinguir un posterior trabajo pictórico en su creador, al perfilar un ulterior trabajo pictórico figurativo que no es solo referencial, sino que propone una novedosa figuración para la pintura de Costa Rica. 


\section{BIBLIOGRAFÍA}

Abbagnano, N. (1974). Diccionario de filosofía. (2. ${ }^{a}$ ed.). México: Fondo de Cultura Económica.

Aguilar, T. \& Báez, E. (2013). Lola Fernández. Revista Perfil. Recuperado de http://www.revistaperfil.com/mujeres_en_portada/Lola_Fernandez_0_4349565 04.html [Consulta 25 may. 2015].

Alcaide, A. (2010). Cómo mirar un cuadro abstracto: Aproximación a la abstracción pictórica mediante el análisis de obras realizadas por mujeres. Revista Creatividad y Sociedad 15 (5), 1-29. Recuperado de http://www.xtec.cat/alfresco/d/d/workspace/SpacesStore/15b5d3de-ff8f-435a80d5-164c9bd4be75/creatividadysociedad_como\%20mirar.pdf [Consulta 25 abr. 2015]

Barzuna, G. (2005). Cultura artística y popular en Costa Rica: 1950-2000 EUCR. San José: EUCR.

Chevalier, J. \& Gheerbrant, A. (2009). Diccionario de los símbolos. (2. ${ }^{a}$ ed.). Edición. Barcelona: Herder.

Consejo Superior Universitario Centroamericano. (1971). Catálogo de la I Bienal Centroamericana de Pintura. San José: CSUCA.

Galería-Valanti. (1998). Lola Fernández 1948-1998: 50 años de pintura. San José.

González, A. (2007). Historia general del arte. San José: EUNED.

Kant, I. (2009). Crítica de la razón pura. Ediciones Colihue SRL.

Lucie, E. (1983). El arte hoy: del expresionismo abstracto al nuevo realismo. Madrid: Cátedra.

Molina, I. (2005). Costa Rica del siglo XX al XXI. Historia de una sociedad. San José: Editorial de la Universidad de Costa Rica. 
Molina, I. (2007). Identidad nacional y cambio cultural en Costa Rica durante la segunda mitad del siglo XX. San José: Editorial de la Universidad de Costa Rica.

Montero, G. (2012). La I bienal centroamericana de pintura. Káñina. Revista de Artes y Letras 36 (extraordinario), 85-89.

Museo de Arte Costarricense. (1974). Lola Fernández retrospectiva: 30 años de pintura. San José.

Real Academia Española. (2001). Diccionario de la Real Academia Española. 22 ed. Vol. 2. Tomo 2, 4, 5, 6, 7, 9 y 10. Colombia: ESPASA.

Rojas, J. M. (2003). Arte Costarricense: Un siglo. San José: Editorial Costa Rica.

Ruhrberg, K. \& Honnef, K. (2005). Arte del siglo XX. Köln: Taschen.

Selva, T. (2011). Rasgos del mundo de la América antigua en la pintura abstracta moderna y contemporánea. VIII Jornadas Nacionales de Investigación en Arte en Argentina. Universidad Nacional de La Plata.

Solano, E. (2014). José Miguel Rojas en el contexto de la neofiguración: pintura y obra gráfica de 1984 a 1997. Káñina. Revista de Artes y Letras 38 (2), 225-238.

Talens, J.; Romera, J.; Tordera, A. \& Vicente, E. (1999). Elementos para una semiótica del texto artístico. Madrid: Cátedra.

Triana, M. A. (2012). Lola Fernández, alquimista. La Nación. Recuperado de http://www.nacion.com/archivo/lola-fernandez-alquimista_0_1300470011.html [Consulta 25 may. 2015].

Ulloa, R. (1979). Pintores de Costa Rica. San José: EUCR.

Ulloa, D. (2012). Museos del Banco Central se engalanan con lo mejor de Lola Fernández. Revista digital de arte y cultura costarricense RedCultura.com. Recuperado de http://redcultura.com/php/Articulos1048.htm [Consulta 25 may. 2015].

Zavaleta, E. (1994). Los inicios del arte abstracto en Costa Rica 1958-1971. San José: Museo de Arte Costarricense. 
Zavaleta, E. (1993). Gestación del arte abstracto en Costa Rica. Káñina. Revista de Artes y Letras 17 (2), 245-265.

Zúñiga, R. (2013). La mirada de Lola. Revista Su Casa. Recuperado de http://www.revistasucasa.com/articulo/especiales/la-mirada-de-lola [Consulta 25 may. 2015]. 